\title{
Gastric fundal heterotopic pancreas mimicking a gastrointestinal stromal tumour (GIST): a case report and a brief review
}

\author{
Duminda Subasinghe ${ }^{1}$, Sivasuriya Sivaganesh ${ }^{1}$, Niranthi Perera ${ }^{2}$ and Dharmabandhu N. Samarasekera ${ }^{\text {* }}$
}

\begin{abstract}
Background: Heterotopic pancreas is a rare congenital condition characterised by pancreatic tissue lacking vascular or anatomic communication with the normal pancreas. Most cases of ectopic pancreas are asymptomatic. The preoperative diagnosis of this condition is difficult.
\end{abstract}

Case presentation: A 50-year-old woman presented with dyspeptic symptoms of 4 years duration. Contrast enhanced CT (computed tomography) scan of abdomen suggested a gastrointestinal stromal tumour in the fundus of the stomach. The patient underwent laparoscopy assisted resection and subsequent histology revealed ectopic pancreatic tissue.

Conclusion: Although heterotopic pancreas is a rare lesion diagnosed on histology, it should be considered in the differential diagnosis of gastric mass lesions and in patients presenting with vague upper gastrointestinal symptoms.

Keywords: Heterotopic pancreas, Stomach, Endoscopy, Surgery

\section{Background}

Heterotopic pancreas is a rare developmental anomaly with a reported incidence of $0.55-14 \%$ at autopsy [1], in approximately one in every 500 upper gastrointestinal surgical specimens and in $0.6-13 \%$ of necropsies [2, 3]. Heterotopic pancreas is referred to as ectopic pancreas, aberrant pancreas, and pancreatic rest. Although it was first described in 1727 by Schultz in an ileal diverticulum, the first histological diagnostic confirmation was described by Klob $[4,5]$ in 1859. It is presence of pancreatic tissue without anatomic or vascular continuity with the normally developed pancreas. Although it is common to occur intra abdominally from anywhere along distal end of the oesophagus to the colon, it has been reported very rarely in extra abdominal sites such as mediastinal cysts, bronchi, lung, umbilicus and brain [6-8]. Intraabdominal HP lesions commonly known to occur intestines although fallopian tubes, lymph nodes and spleen

\footnotetext{
*Correspondence: samarasekera58@yahoo.co.uk

${ }^{1}$ University Surgical Unit, The National Hospital of Sri Lanka, 28/1, Ishwari

Road, Colombo, Sri Lanka

Full list of author information is available at the end of the article
}

were rare sites [9]. Out of gastrointestinal lesions, commonest area is upper gastrointestinal tract i.e. stomach (30\%), duodenum (25\%) and jejunum (15\%). At rare instances it can also occur in association with hepatobiliaty organs such as liver, gallbladder, common bile duct, cystic duct [9].

Heterotopic pancreas is usually found incidentally and is generally asymptomatic. However it may become symptomatic when complicated by inflammation, bleeding, obstruction or malignant transformation [10, 11]. The most common heterotopic site is the stomach commonly involving antrum and prepyloric region on the greater curvature or posterior wall [12].

\section{Case presentation}

A 50-year-old woman presented with burning epigastric pain, loss of appetite and associated GORD (gastro-oesophageal reflux disease) symptoms for 4 years duration. She had a history of worsening symptoms of severe dyspeptic symptoms. There was no history of loss of appetite, post prandial vomiting or gastrointestinal bleeding. Previously she had undergone several 
upper GI (Gastrointestinal) endoscopic examinations at a local hospital for epigastric pain, dyspeptic symptoms and found to have a hyperplastic polyp on biopsy. She gave a history of diabetes mellitus with satisfactory glycaemic control on oral hypoglycaemic drugs. She was on long standing proton pump inhibitors and antacids to relieve symptoms. Physical examination was unremarkable. Her routine laboratory investigations were normal. Upper gastrointestinal endoscopy showed an elevated area of mucosa resembling a sessile polyp in the gastric fundus and an adjacent diverticulum (Fig. 1). On upper GI endosonography (Fig. 2), a solid mass in the region of the gastric fundus was visualized. Contrast enhanced CT scan of abdomen (Fig. 3) showed a welldefined predominantly homogenously enhanced area (Hounsfield 60 unit) on the anterior wall of the stomach in the region of the fundus. Other abdominal organs including pancreas were normal. The operative plan was to perform on table upper GI endoscopy followed by laparoscopic wedge excision of the fundal mass. Diagnostic laparoscopy was normal. There were no regional lymph node enlargement or peritoneal deposits. Other pelvic organs appeared normal on laparoscopy. Laparoscopic surgery (Fig. 4) was converted to open approach due to the bleeding from the short gastric vessels and wide local excision of the mass $(1.6 \times 1.5 \times 1 \mathrm{~cm})$ with a small cuff of the stomach (Fig. 5) was carried out. The post operative period was uneventful and she was discharged on post operative day seven. Histological examination of the specimen (Fig. 6) revealed a heterotopic pancreatic tissue $(1 \times 2 \times 3 \mathrm{~cm})$ in the submucosa and muscularis propria of the stomach. Heterotopic pancreatic tissue comprised of acinar and ductal structures together with scattered islets of langerhan. Her

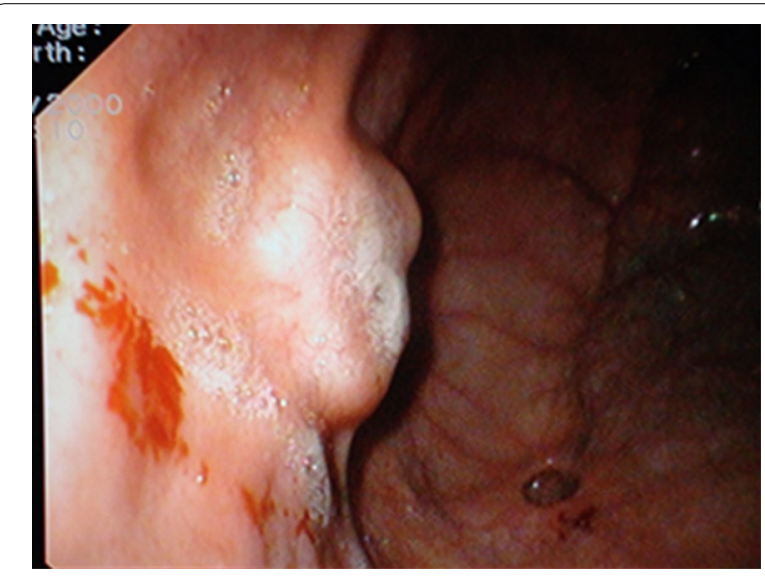

Fig. 1 Upper gastrointestinal endoscopy showing gastric fundal mass

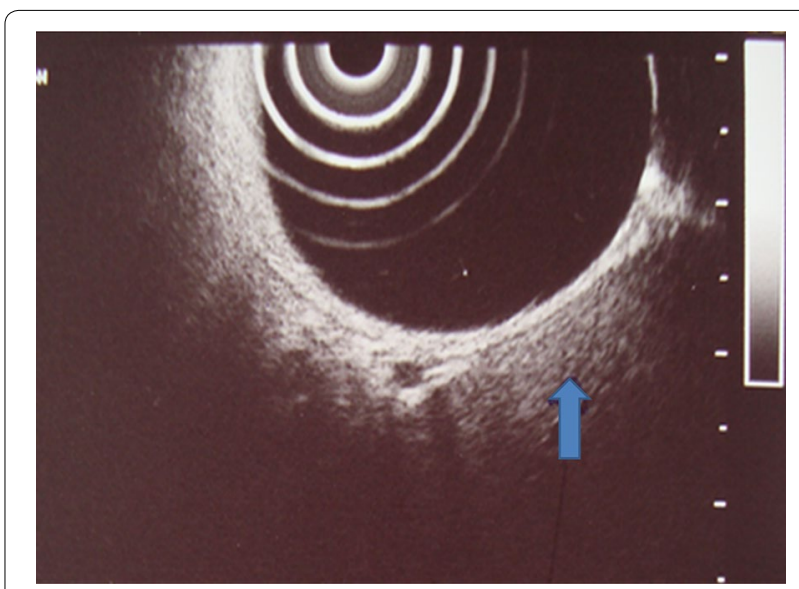

Fig. 2 Upper Gl endosonography showing a mass lesion in the fundus of stomach

post-operative period was uneventful and she was discharged on 4th post-operative day.

\section{Discussion}

Although several theories have been proposed to explain the pathogenesis, the exact causes of heterotopic pancreas are still not recognized. Embryological basis for heterotopic pancreas is believed to arise during rotation of the foregut, when fragments of the pancreas become separated from the main body and are deposited at ectopic sites [11, 13]. Gastric antrum is the commonest site for heterotopic pancreatic tissues in stomach which accounts about 85-95\%, being more common along the greater curvature. Our patient had the lesion in the anterior wall of stomach near fundus. The symptoms of this entity depend upon the anatomical location

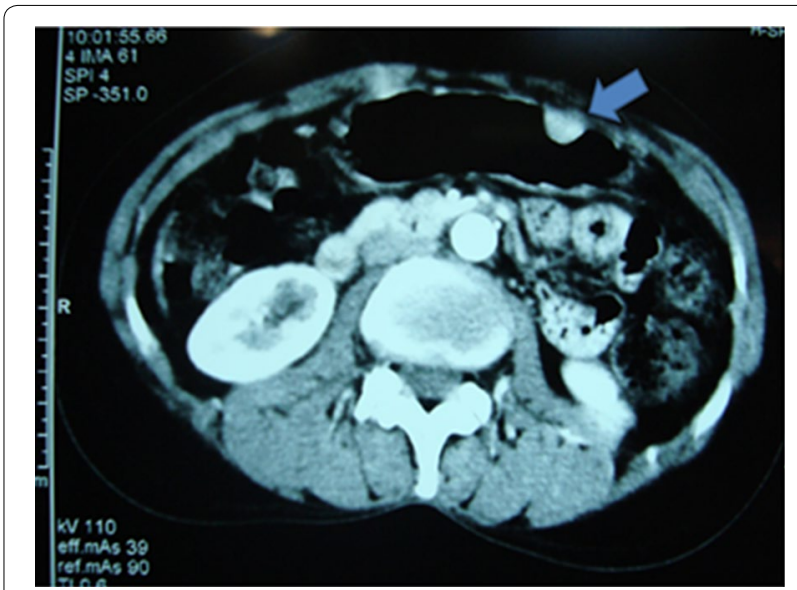

Fig. 3 Contrast CT abdomen showing enhancing mass on the anterior gastric wall 


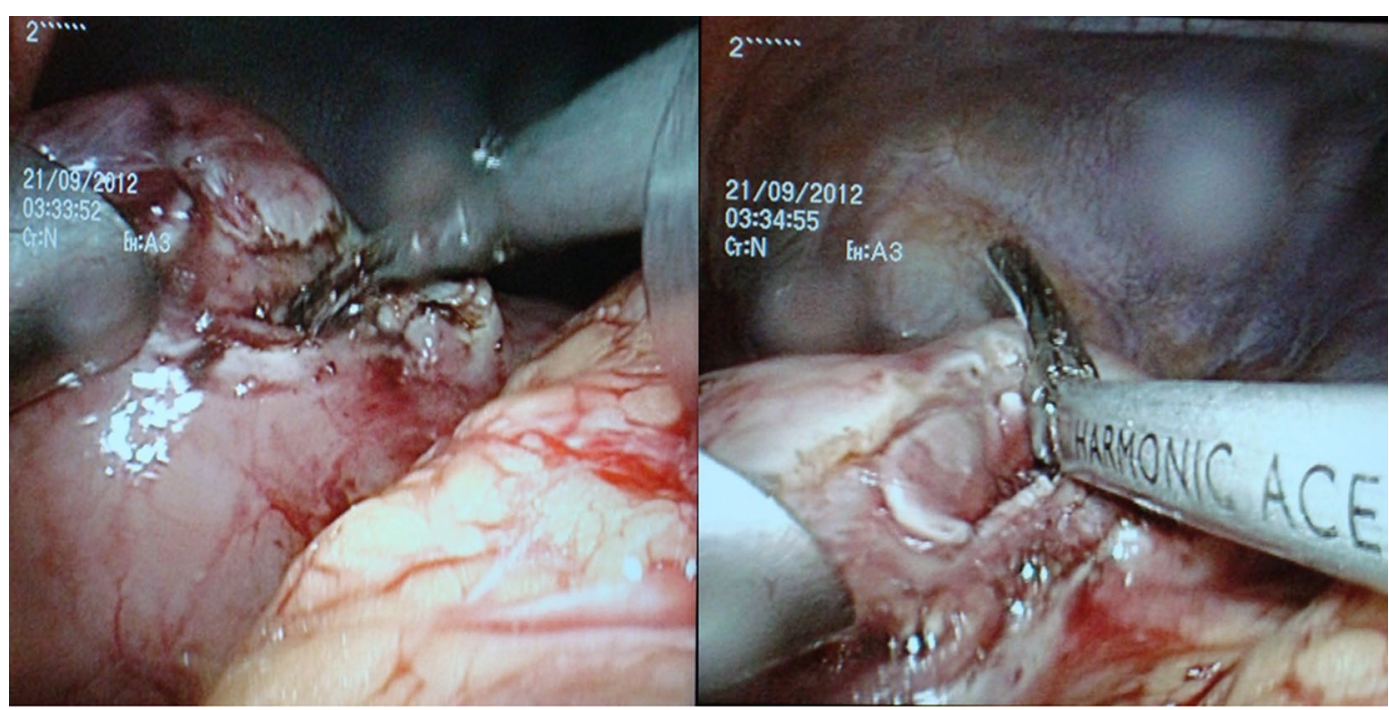

Fig. 4 Laparoscopic resection of the gastric fundal mass

and are nonspecific. The diagnosis of ectopic pancreas is difficult despite the development of modern diagnostic methods such as computerized tomography, ultrasonography, and endoscopic ultrasonography because they are not very specific in the diagnosis. Therefore it remains a diagnostic challenge. Endoscopic examination has become useful adjunct in the evaluation of submucosal lesions. The endoscopic picture of heterotopic pancreas usually reveals broad-based, umbilicated, firm, slightly irregular submucosal lesion in the stomach, or elsewhere in the gastrointestinal tract. Although positive biopsy establishes the diagnosis, in most cases, biopsies are superficial and therefore non-diagnostic. The main

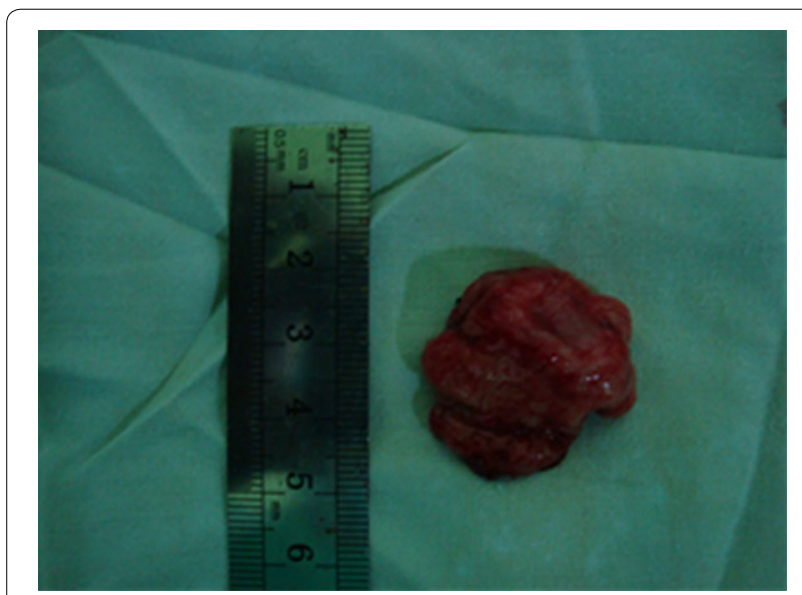

Fig. 5 Resected specimen containing tumour differential diagnosis for heterotopic pancreatic tissue includes gastrointestinal stromal tumours, gastrointestinal autonomic nerve tumour, gastric carcinoids, lymphoma or gastric carcinoma which can be misinterpreted on imaging studies or endoscopic examinations [14, 15]. There are predictive features on $\mathrm{CT}$ such as prominently enhancing overlying mucosa, location, growth pattern, and lesion border which helps in the differentiation of HP tissue from GIST (gastrointestinal stromal tumour) and leiomyoma [16]. Generally it has been suggested that heterotopic pancreas in the stomach is difficult to differentiate from other submucosal tumors on CT as happened in our patient. Therefore symptomatic patients require surgical exploration in order to obtain a definitive diagnosis and to exclude malignancy. Local excision is adequate for benign looking lesions [16]. The management of asymptomatic, incidentally detected HP remains a debate although some evidence suggested in resection of these asymptomatic cases to prevent future complications [4, $5,11,12]$. The synchronous occurrence of gastrointestinal stromal tumour (GIST) and heterotopic pancreas has been reported once [17]. To our knowledge this is the first case report of a heterotopic pancreatic tissue mimicking a GIST in a patient with diabetes mellitus.

\section{Conclusions}

Heterotopic pancreatic tissue is an incidental rare lesion and gastric fundal site makes it more peculiar and rare. Despite the improvements in the diagnostic endoscopy and cross sectional imaging, it still remains a challenge 

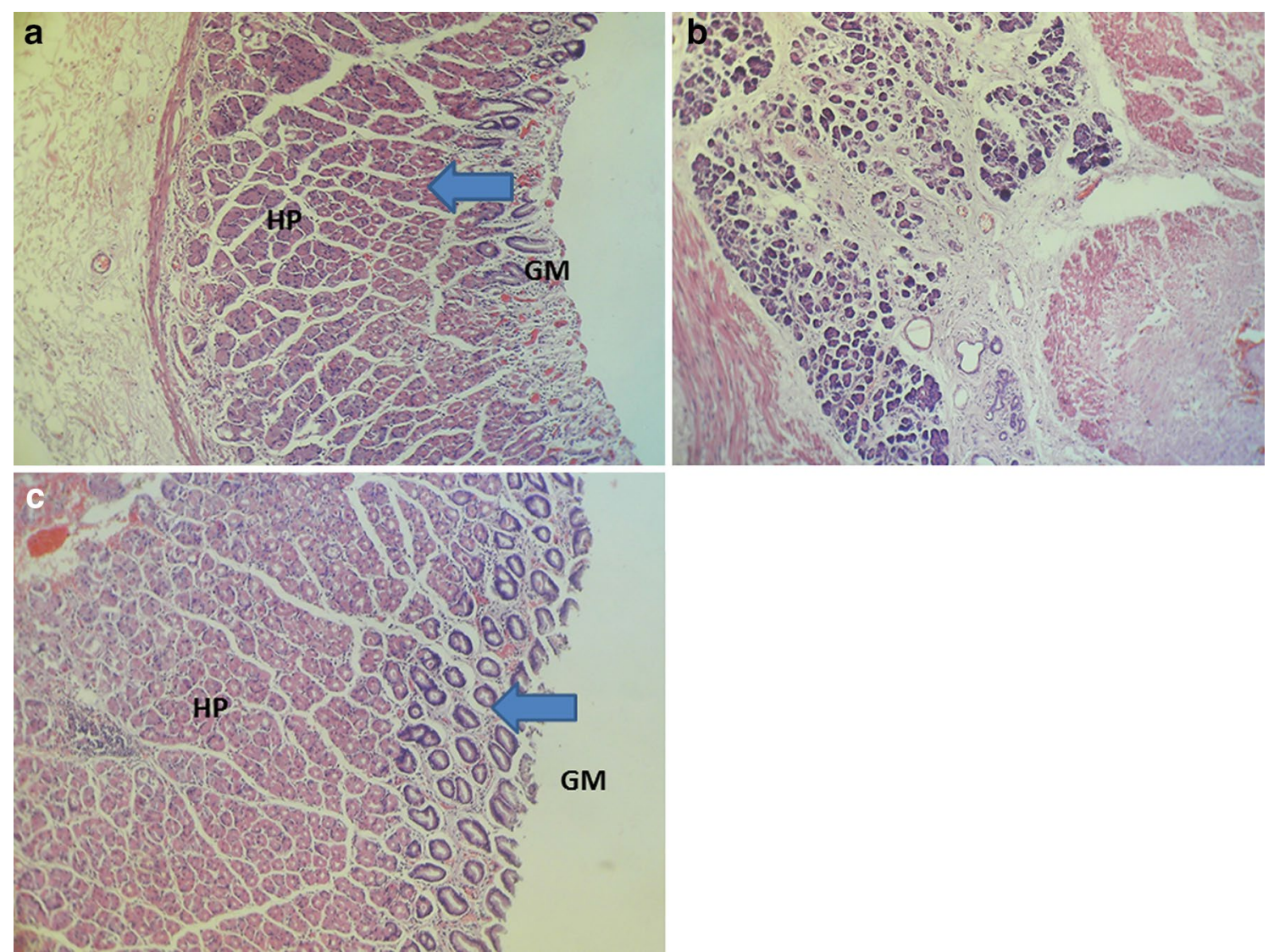

Fig. 6 Heterotopic pancreatic tissue (HP) in the submucosa of stomach (a, b). c Heterotopic pancreatic tissue (HP) in the muscularis propria (MP), GM Normal gastric mucosa with glands

to differentiate ectopic pancreatic tissue from neoplasms such as GIST. Therefore it prudent to consider it as a differential diagnosis of gastric mass lesions and in patients presented with vague upper gastrointestinal symptoms.

\section{Consent}

We have obtained informed written consent from the patient for publication of this case report and accompanying images.

\section{Authors' contributions}

All authors were involved in planning, analysis of case and writing the manuscript. The authors have nothing to disclose. DS wrote the manuscript. All authors were contributed to management of the patient. DNS and SS provided overall supervision and edited the final version of the manuscript. NP involved in the histo-pathological diagnosis. All authors read and approved the final manuscript.

\section{Author details}

${ }^{1}$ University Surgical Unit, The National Hospital of Sri Lanka, 28/1, Ishwari Road, Colombo, Sri Lanka. ${ }^{2}$ Department of Pathology, Faculty of Medicine, University of Colombo, Colombo, Sri Lanka.

\section{Acknowledgements}

The authors acknowledge all the ward staff who took care of our patient.

\section{Competing interests}

The authors declare that they have no competing interests.

Received: 12 October 2015 Accepted: 16 March 2016

Published online: 22 March 2016

\section{References}

1. Low G, Panu A, Millo N, Leen E. Multimodality imaging of neoplastic and nonneoplastic solid lesions of the pancreas. Radiographics. 2011;31:993-1015.

2. Shetty A, Paramesh AS, Dwivedi AJ, et al. Symptomatic ectopic pancreas. Clinical. Review. 2002;58:203-7.

3. Tanaka K, Tsunoda T, Eto T, et al. Diagnosis and management of heterotopic pancreas. Int Surg. 1993;78:32-5.

4. Klob L. Pancreas accesorium. Zeitschrift der Kaiserl. Konigl. Gesellschaft der Aerzte zu Wien. 1859;15:732.

5. Caberwal D, Kogan SJ, Levitt SB. Ectopic pancreas presenting as an umbilical mass. J Pediatr Surg. 1977;12(4):593-9.

6. Heller RS, Tsugu H, Nabeshima K, Madsen OD. Intracranial ectopic pancreatic tissue. Islets. 2010;2(2):65-71.

7. Jaschke W, Aleksic M, Aleksic D. Heterotopic pancreatic tissue in a bronchogenic cyst-diagnosis and therapy. Thorac Cardiovasc Surg. 1982;30(1):58-60.

8. Szabados S, Lenard L, Tornoczky T, Varady E, Verzar Z. Ectopic pancreas tissue appearing in a mediastinal cyst. J Cardiothorac Surg. 2012;7:22. 
9. Hsia CY, Wu CW, Lui WY. Heterotopic pancreas: a difficult diagnosis. J Clin Gastroenterol. 1999;28:144-7.

10. Emerson L, Layfield LJ, Rohr LR, Dayton MT. Adenocarcinoma arising in association with gastric heterotopic pancreas: a case report and review of the literature. J Surg Oncol. 2004;87:53-7.

11. Papaziogas B, Koutelidakis I, Tsiaousis P, Panagiotopoulou K, Paraskevas G, Argiriadou H, Atmatzidis S, Atmatzidis K. Carcinoma developing in ectopic pancreatic tissue in the stomach: a case report. Cases $\mathrm{J}$. 2008; 1 (1):249.

12. Galatioto C, Goletti O, Franceschi M, Buccianti P, Neri E, et al. Laparoendo scopic treatment of gastric ectopic pancreas. Surg Laparosc Endosc Percutan Tech. 1999;9:160-4.

13. O'Reilly DJ, Craig RM, Lorenzo G, Yokoo H. Heterotopic pancreas mimicking carcinoma of the head of the pancreas: a rare cause of obstructive jaundice. J Clin Gastroenterol. 1983;5(2):165-8.
14. Christodoulidis G, Zacharoulis D, Barbanis S, Katsogridakis E, Hatzitheofilou K. Heterotopic pancreas in the stomach: a case report and literature review. World J Gastroenterol. 2007;13(45):6098-100.

15. Kim JY, Lee JM, Kim KW, et al. Ectopic pancreas: CT findings with emphasis on differentiation from small gastrointestinal stromal tumor and leiomyoma. Radiology. 2009;252:292.

16. De Friend DJ, Saa-Gandi FW, Humphrey CS, Foster DN. Symptomatic pancreatic heterotopia treated by local excision. Gut. 1991;32:332-3.

17. Kaufman A, Storey D, Lee CS, Murali R. Mucinous cyst exhibiting severe dysplasia in gastric heterotopic pancreas associated with the gastrointestinal stromal tumour. World J Gastroenterol. 2007;13(43):5781-2.

\section{Submit your next manuscript to BioMed Central and we will help you at every step:}

- We accept pre-submission inquiries

- Our selector tool helps you to find the most relevant journal

- We provide round the clock customer support

- Convenient online submission

- Thorough peer review

- Inclusion in PubMed and all major indexing services

- Maximum visibility for your research

Submit your manuscript at www.biomedcentral.com/submit
() Biomed Central 